Now that genetic engineering is available, biologists are benefiting. By attempting to create synthetic genetic systems, we will learn more about how natural genetic systems work; by attempting to create synthetic metabolisms, we learn about how natural metabolisms work; by attempting to create synthetic regulatory circuits, we learn about how natural regulatory circuits work.

Will we ever understand what life is? Just as with Schrödinger's book, Regis' text will not be the last word. It is, however, a good place for a lay reader to start, one who welcomes the ambition of its title.

Steven Benner is a distinguished fellow at the Foundation for Applied Molecular Evolution and the Westheimer Institute for Science and Technology, Gainesville, Florida 32601, USA, and co-author of The Limits of Organic Life in Planetary Systems.

\title{
Bottling the nuclear demon
}

\section{Why Nuclear Disarmament Matters by Hans Blix}

MIT Press: 2008.97 pp. \$14.95, £9.95

\section{On Nuclear Terrorism \\ by Michael Levi \\ Harvard University Press: 2007. 210 pp. \\ $\$ 24.95, \notin 16.95$}

\section{Martin van Creveld}

Right or wrong, nuclear proliferation is much in the news. These two works tackle the problem head on. The first is a somewhat emotional call to prevent proliferation from proceeding further and, if possible, to reverse it. The second deals with some of the problems to which it may give rise.

To the readers of Nature, as well as anybody who is familiar with the origins of the second Iraq War, Hans Blix needs no introduction. In 2002-04, the elderly, genial Swedish diplomat, former foreign minister and former head of the International Atomic Energy Agency, found himself at the head of the UN Monitoring, Verification and Inspection Commission (UNMOVIC), charged with finding weapons of mass destruction in Iraq. Announcing that he had failed to discover any and that they almost certainly did not exist, he had to confront the full wrath of the Bush administration - a story that throws an ugly light on that administration while showing Blix himself in a very positive one.

A reader looking at the title of Blix's new work might be forgiven for thinking that he provides a retrospective account of several decades-worth of effort to put the nuclear demon back into the bottle from which it had escaped. He does nothing of the kind. First, contrary to his promise, he does not focus on nuclear weapons alone but widens the discussion - and, to my mind, weakens his case - by including chemical and biological ones too. Second, part of the book has little to do with nuclear disarmament but constitutes a polemic against the Bush administration's attempt to develop a national strategy based on pre-emption. Given how slim the volume is - in reality, it is just a brochure - this leaves little room for a serious discussion of nuclear disarmament, why it matters and what steps towards its realization should be taken next.

Furthermore, Blix is what the Germans call a Gutmensch - a do-gooder. From his perch in lucky Sweden, he observes the world with a benign smile and gently seeks to teach other benighted people how to improve it. One may certainly respect this position. On the other hand, it is neither the only one possible nor necessarily the one best suited for dealing with future nuclear-armed Adolf Hitlers, Joseph Stalins, and, yes, Saddam Husseins as well.

To put it bluntly, Blix is no strategist. As he himself comes very close to saying at the beginning of this book, he thinks in terms of morality and well-being, not of power. Not once does he mention deterrence. In other words, the fact that, had it not been for nuclear-weapons proliferation, World War Three might very well have broken out long ago and perhaps obliterated both his native country and himself.

A much younger man than Blix, Michael Levi is almost unknown. The cover of his book merely says that he is "Fellow for Science and Technology at the Council on Foreign Relations, New York". From an Internet search, we learn that he is an academic who has worked here and there and published this and that. Yet anyone who reads his work cannot but be impressed by his deep understanding of nuclear terrorism and the possibilities of dealing with it.

Levi's work is written in a calm, unemotional and somewhat dry manner. Those looking for hair-raising accounts of how

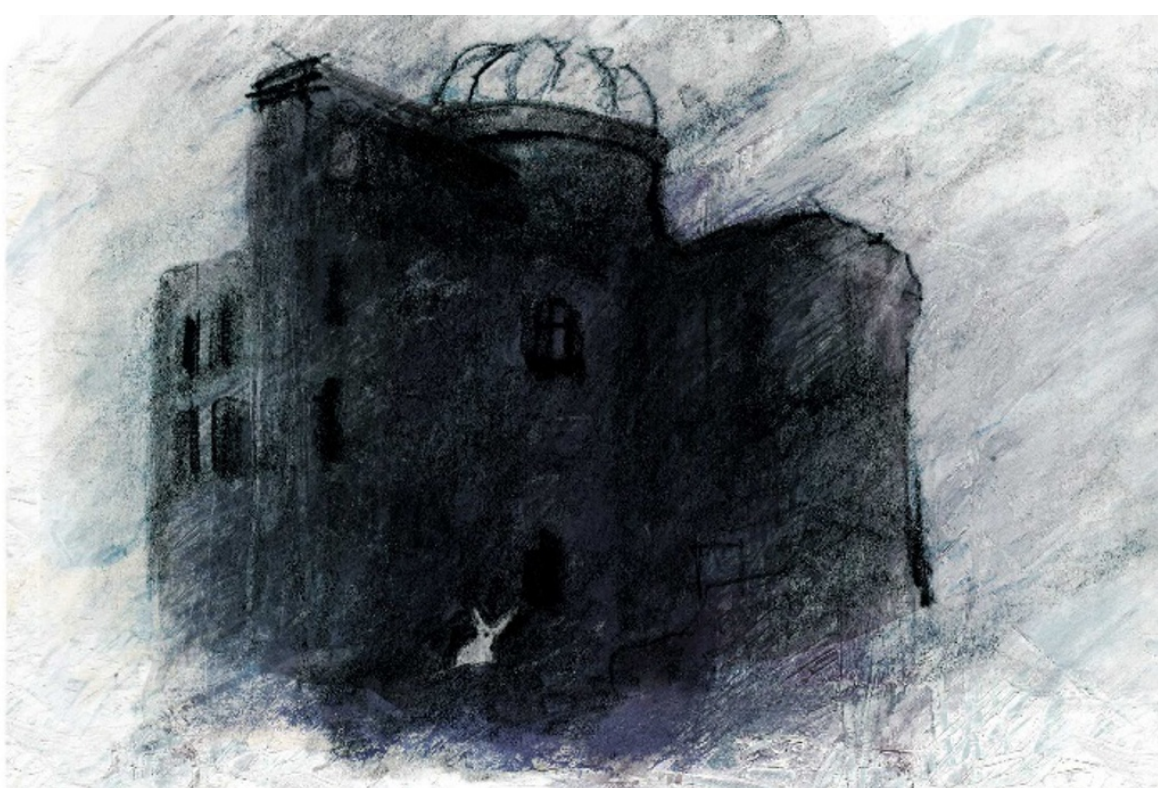

Doomsday Men: The Real Dr Strangelove and the Dream of the Superweapon

by P. D. Smith (Allen Lane, $€ 8.99$ )

In the 1950s, humans became capable of destroying life. Smith describes the first weapons of mass destruction and how the doomsday bomb became a symbol of science's destructive power. "The book is as much a history of modern science as of modern weaponry", wrote Gregg Herken (Nature 448, 868; 2007).

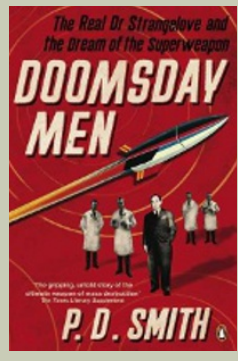

The Soulful Science: What Economists Really Do and Why It Matters

by Diane Coyle (Princeton Univ. Press, $\$ 19.95$ ) Economics is not a dry science but a human one, says Coyle. By incorporating psychology, evolution and complexity, economists are in the best position to model human society. Frances Cairncross wrote: "To understand how the big ideas of the past half-century fit together ... read this book" (Nature 447, 1057; 2007).

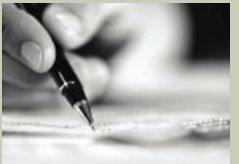

The Soulful Science what r:acrmbis Roully no an vilye r. vall DIANE COYLE 
bad terrorists almost succeeded in blowing up the world but were prevented from doing so at the last moment by good policemen and other intelligence personnel will be disappointed. Indeed it is one of Levi's strong points that, from beginning to end, he does not engage in any kind of mystery-solving or moralizing. What he does provide is a stepby-step account of the many possibilities of using nuclear bombs and materials for terrorist ends and of at least some of the things that can be done to prevent those possibilities from being realized.

To cut a long story short, Levi sees many serious obstacles standing in the way of would-be nuclear terrorists. They start with the near impossibility of producing (as distinct from purchasing or stealing) high-grade uranium and plutonium; they end with the fact that any nuclear weapon a terrorist may build will almost certainly be crude, very heavy (and thus difficult to conceal and to move) and, quite possibly, unreliable as well. Other possibilities such as a 'dirty' bomb also exist, but compared with a full-scale bomb they are relatively harmless.

That is the good news. The bad news, Levi tells us, is that nuclear terrorism is not impossible in principle. Nor will any set of precautions, however well considered, provide $100 \%$ security against it.

Levi's argument may be boiled down to five propositions. First, policy-makers should make "the strongest possible efforts to improve controls over nuclear weapons and materials and prevent their further spread". Second, strategic assessments of the threat should avoid the mistake of concentrating solely on the worst possible scenario. Instead, they should also consider the most likely ones and, to encourage thought and cooperation, as far as possible those assessments should be made public. Third, if nuclear terrorism is to be prevented, it is necessary to set up a global system. The more governments cooperate and the more numerous and varied the obstacles they confront terrorists with, the greater the chances of success. Fourth, even imperfect countermeasures are better than none, because they may well sound the alarm.

Fifth and perhaps most controversial, it is important that thought be devoted, and steps taken to reduce damage from nuclear terrorist acts after they have taken place - given that, in Levi's view, some such steps should be able to dramatically reduce casualties.

Levi's measured text does not rely heavily on mathematics, and he has hidden the few equations he uses in the appendix. Still, here and there the book, with its flat tone and relatively few verbs, is not altogether easy to understand. Moreover, as he notes, there are certain things that might be useful to terrorists and that, accordingly, he cannot say. These are minor shortcomings if, indeed, they are shortcomings at all. Although the volume will not enjoy a wide readership, for anyone with a serious interest in the possibilities of nuclear terrorism and how to prevent it, On Nuclear Terrorism is a must.

Both authors assume that nuclear proliferation is bad. In Blix's case, this is because it just is so; in Levi's, because it increases the chances of nuclear terrorism. Neither gives a thought to the possibility that proliferation and the balance of terror have actually been excellent things - perhaps the best that ever happened to mankind. The difference between them is that, given Levi's theme, his ignoring this entire question is apt. In the case of Blix, it is certainly not.

Martin van Creveld is professor emeritus of the Hebrew University, Jerusalem 91905, Israel. His most recent book is The Changing Face of War: Lessons of Combat, From the Marne to Iraq.

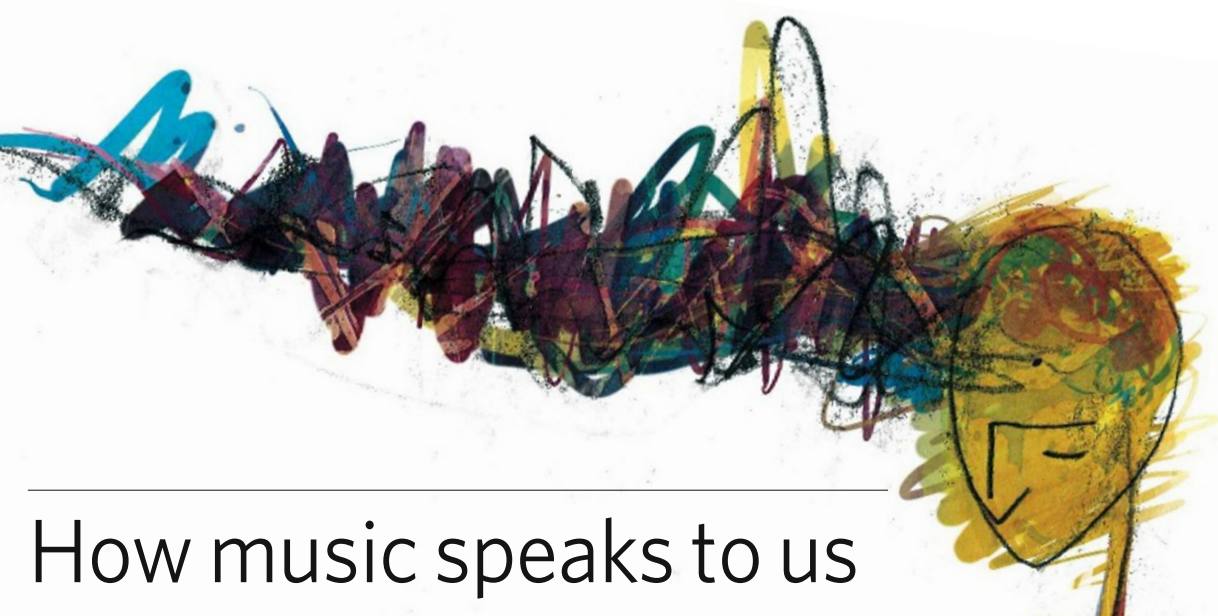

\section{Music, Language, and the Brain \\ By Aniruddh D. Patel \\ Oxford University Press: 2008. 528 pp. $\$ 59.95$}

\section{David Poeppel and Elika Bergelson}

This book is an intellectual tour de force, raising many more issues than recent popular works by, for example, Oliver Sacks and Daniel Levitin. Not one for the bus, beach or bathtub, Music, Language, and the Brain requires focused engagement, but its rewards are rich. Aniruddh Patel offers a thorough analysis of music cognition and its relation to language, and outlines an ambitious and innovative research programme that deepens our understanding of cognition in general.

Music and speech share basic sound elements, and Patel starts by highlighting the similarities and differences between how auditory signals work. The book then delves into five topics: rhythm, melody, syntax, meaning and evolution. Each topic is examined within the context of music and language, to see how key cognitive processes overlap or diverge. By evaluating

the latest empirical evidence, the author proposes further studies to test or extend previous results - experimentation, he says, is crucial in moving this field forward. Clearly, Patel has particular theories that he favours, but he describes fairly the ideas of others. The book is admirably clear in stating what has been done, and what needs to be done.

The belief that there are fundamental similarities in the processing of music and language is largely intuitive and worth testing. Both have been argued to be unique to humans. The book

\section{Second Nature: Brain Science and Human Knowledge}

by Gerald M. Edelman (Yale Univ. Press, $\$ 13$, E8.99)

Nobel prizewinner Gerald Edelman offers a new theory of knowledge based on brain science. He shows how advances in neuroscience and physiology have led to a greater understanding of the brain, consciousness and creativity.

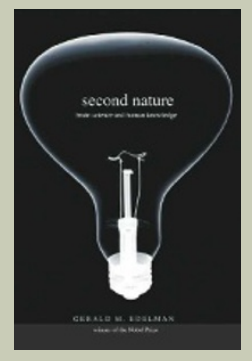

\section{Skin: A Natural History}

by Nina G. Jablonski (Univ. California Press, £9.95)

Nina Jablonski explores skin's many purposes, such as its role in touch and emotional display, and explains them as the result of billions of years of evolutionary compromise. "Skin is not just about biology, but also the way we live," wrote John Galloway (Nature 445, 367-368; 2007).

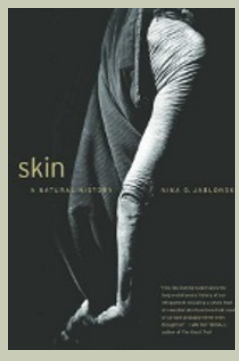

